\title{
Target strengths of Antarctic krill (Euphausia superba) at 38 and $120 \mathrm{kHz}$
}

\author{
Kenneth G. Foote \\ Institute of Marine Research, 5024 Bergen, Norway \\ Inigo Everson, Jonathan L. Watkins, and Douglas G. Bone \\ British Antarctic Survey, High Cross, Madingley Road, Cambridge CB3 OET, United Kingdom
}

(Received 18 May 1989; accepted for publication 27 September 1989)

\begin{abstract}
Encaged aggregations of live krill in good to pristine condition have been ensonified at 38 and $120 \mathrm{kHz}$. Concurrent underwater television observations of behavior resemble those made by underwater divers in naturally occurring swarms, with comparably high densities of the order of $10^{4}$ animals $/ \mathrm{m}^{3}$. Mean, single-animal target strengths have been inferred from measurements of echo energy. For aggregations with mean lengths in the range $[30,39] \mathrm{mm}$, the mean single-krill target strengths are in the range $[-88,-83] \mathrm{dB}$ at $38 \mathrm{kHz}$ and $[-81,-74] \mathrm{dB}$ at $120 \mathrm{kHz}$. Collateral measurements on some of the same encaged specimens determined a density contrast of $1.0357 \pm 0.0067$ and sound-speed contrast of $1.0279 \pm 0.0024$, relative to seawater. These numbers have been used with the fluid-sphere model as stated by Greenlaw [Limnol. Oceanogr. 24, 226-242 (1979) ] . Computed backscattering cross sections have been averaged over the length distributions of each measured aggregation, resulting in target strength predictions in the range $[-86,-80] \mathrm{dB}$ at $38 \mathrm{kHz}$ and $[-79,-76] \mathrm{dB}$ at $120 \mathrm{kHz}$.
\end{abstract}

PACS numbers: 43.20.Fn, 43.30.Xm, 43.80.Jz

\section{INTRODUCTION}

Krill is a very abundant animal. Its annual production is estimated to be many times the world fish catch,, ${ }^{1,2}$ yet current estimates of its abundance vary as widely as those described by Everson in $1977 .^{3}$

In 1981, an attempt was made to improve the knowledge of krill abundance and indicate acoustic surveying methods. The results from this effort, called the First International BIOMASS Experiment (FIBEX), have been questioned partly because of uncertainty about the mean backscattering cross section or target strength of the animal.

At the time of the Post-FIBEX Acoustic Workshop in 1984 , there were only several published values for the target strength of $E$. superba., ${ }^{4,5}$ Revision of earlier estimates was attempted on the basis of these numbers, after adjustment of one of these for a reported error in calibration and after addition of laboratory measurements on preserved specimens of $E$. superba, ${ }^{6}$ tank measurements of $E$. pacifica, ${ }^{7}$ measurements on tethered specimens of live freshwater shrimp ${ }^{8,9}$ and live and defrosted Thysanoessa specimens and Meganyctiphanes norvegica ${ }^{10}$ and certain expectations based on quasiempirical modeling. ${ }^{10}$ Combination of the various data is described in Ref. 11, and further discussed by Everson in Ref. 12.

Estimates of target strength computed from the revised target strength-length relation struck these authors as being very large, from both theoretical and empirical evidence. Model computations by Greenlaw, reported in Ref. 13, indicated that the post-FIBEX prediction of target strength for a $35-\mathrm{mm}$ krill at $120 \mathrm{kHz}$ was very roughly $10 \mathrm{~dB}$ too high.
Acoustic estimates of abundance around South Georgia have been significantly less than the predators were estimated to be consuming. This was the background for the authors' proposal of the krill target strength experiment, which they conducted under the aegis of British Antarctic Survey at Stromness, South Georgia, during the austral summer 1987-1988.

The purpose of the experiment was to determine the target strength of krill by measuring the echo energy from encaged aggregations of living $E$. superba. A secondary aim was to measure the sound speed in the same animal for possible collateral use in modeling work. The design of the experiment, its execution and results, and simple model computations using the observed values of density and sound-speed contrasts are presented here.

\section{EXPERIMENTAL DESIGN}

Earlier studies on the target strength of euphausiids and other small crustaceans convinced the authors of the need to measure the animal, $E$. superba, itself. The work of Kogeler et $a l .{ }^{14}$ was noted for its finding of systematic variations in density of euphausiids and the copepods Calanus finmarchicus and $C$. hyperboreus with size and season. The same is presumed true of $E$. superba, as systematic variations in biochemical composition are known. ${ }^{15-17}$ The density and sound speeds of zooplankton are close to the respective seawater values, ${ }^{14,18}$ hence, the precise zooplankton values, as well as small deviations from these, can be very significant in the context of echo formation. ${ }^{19}$ This is why the krill target strength experiment was staged south of the Antarctic Con- 
vergence, where $E$. superba lives, and why the density, sound speed, and other properties of the experimental subjects were measured.

Euphausiid properties tabulated in Refs. 14 and 18 suggested that the density and sound-speed contrasts for $E$. superba would also be quite low. Acoustic scattering must inevitably be weak, hence, it was decided to measure encaged aggregations of krill. Plans to measure single krill were abandoned when the lowness of the target strength became apparent.

Observation of directionality in scattering by euphausiids $^{7,20}$ also influenced the experimental design. The attempt would be made to observe the orientation of krill, through a statistical distribution, concurrently with the acoustic measurements.

Clearly, the ideal measurement site would be a sheltered bay, with near-ocean-quality seawater, permitting raft operation, with accessible shore and comparatively little fresh water runoff from land. This combination was found at Stromness Harbor on South Georgia. The presence, in the abandoned whaling station, of several more or less intact buildings, for accommodations, laboratory, and equipment store, was a further inducement to adopt the site.

The decision to measure encaged aggregations of krill allowed a wealth of experience with encaged fish to be tapped, as represented in the bibliography in Ref. 21. In addition, an experiment with encaged fish, ${ }^{22}$ could serve as a model for the present experiment. This was mostly followed, the major exceptions being that the transducer beams were oriented downward and that the target strength of single animals was not measured.

\section{MATERIALS}

\section{A. Experimental site}

The primary measurements were made from a raft moored securely $200 \mathrm{~m}$ from shore in 50-m-deep water in the harbor at Stromness on South Georgia. The site was protected from the open sea by an island blocking most of the harbor mouth. Swell with amplitude up to $0.5 \mathrm{~m}$ did pass through, however. The site was subject to violent catabatic winds rushing down the large and open valley behind Stromness. These reached severe gale force on roughly one out of two days, and hurricane force about once a fortnight. Depending on the wind direction and temperature, the immediate surface layer in the harbor could become quite brackish owing to glacial runoff. However, this low-density layer was seldom thicker than about $1 \mathrm{~m}$, and did not affect the conduct of the measurements, which were performed far below it.

\section{B. Krill supply and maintenance}

Although krill frequently occur around South Georgia, their presence in bays, such as Stromness, is unpredictable. Fresh supplies of good-condition, live krill were obtained by the RRS JOHN BISCOE at approximately fortnightly intervals throughout the experiment. Krill captured by trawling were immediately put into seawater tanks on the trawling deck. Dead or damaged krill were removed from the tanks while the ship was at sea. Swimming krill in good condition were transferred to the holding pens when the ship returned to Stromness.

This supply was augmented by fortuitous swarms of krill in the harbor. On each such occasion it was possible to attract the krill at night by surface lights to the very edge of the holding pens, where the krill could be caught by dip net and transferred in the freshest condition. It was estimated that 500000 krill were secured after about $1 \mathrm{~h}$ on each occasion.

The krill were kept in a cluster of four holding pens. Each was cylindrical in form, with 2-m diameter and 3-m depth. An air pump, driven by generator ashore, lifted water from 16-m depth to above the surface, where its fall into the pen entrained additional air. The rapid growth of algae on the sidewalls of the pens provided a source of food for the krill, which were frequently observed to be grazing on this.

A seine was hung around the holding pens and closed at the bottom. This and a fine-mesh covering of the surface openings protected the krill from predators such as penguins and seals.

\section{Cage}

Useful acoustic measurements were obtained with each of two identical cages. These were right octagonal cylinders of $0.5-\mathrm{m}$ height and $0.5-\mathrm{m}$ diameter, measured between opposite sides. The volume was thus $0.104 \mathrm{~m}^{3}$.

The material used in the construction was plastic netting of rectangular grid $3.2 \times 3.6 \mathrm{~mm}$. This was procured from Internet Incorporated, Minneapolis, Minnesota. The netting, product number $\mathrm{ON}-8630$, is normally used in reinforcing paper, as for toweling.

The cages were constructed by sewing, with monofilament nylon, precut octagonal end panels of the mesh to the long edges of a precut rectangular panel, which formed the sidewall. The sidewall was closed by sewing with the same monofilament nylon.

\section{Measurement configuration}

The cage was suspended roughly $6 \mathrm{~m}$ below the transducers, which were mounted on a heavy frame from which other gear was suspended. The cage itself was suspended between two lightweight square frames, $3 \mathrm{~m}$ on a side. Lines of monofilament nylon were attached to each of the 16 corners. The upper eight were attached to a superior frame, the lower eight to the inferior frame. An underwater television camera was suspended from the inferior frame, pointing upward toward the cage. The entire rig was suspended by a single rope attached to the transducer frame and allowing raising and lowering by a winch attached to a gantry positioned over one of two identical $4 \times 4-\mathrm{m}$-square moonpools on the raft. The normal operating depth of the transducers was $9 \mathrm{~m}$.

\section{E. Echo sounding and integrating instruments}

It was desired to use the same kind of instruments for the measurements as are typically used during surveys. This was done with the SIMRAD EK-400 echo sounder ${ }^{23}$ normally used on board RRS JOHN BISCOE. The echo sounder 
was used in its dual $38-$ and $120-\mathrm{kHz}$ modes together with UNIVERSAL SONAR transducers, each with nominal 10deg beamwidth. Integration of the squared echo signals was performed with the SIMRAD QD digital echo integrator. ${ }^{24}$ Both echo sounder and integrator were housed ashore, in the laboratory, together with other equipment. This included a British Antarctic Survey-built system for display and logging of data. The cable link was entirely satisfactory. Additional acoustic gear consisted of three calibration spheres: 60- and 23-mm-diam copper spheres ${ }^{25}$ and a 38.1-mm-diam precision ball bearing made of tungsten carbide with $6 \%$ cobalt binder. ${ }^{26}$

\section{F. Environmental monitoring equipment}

For continual measurement of temperature and salinity at cage depth, a Plessey CTD-sonde, model number 9041$12 \mathrm{~B}$, was used. A light sensor was attached to the sonde. This was based on a noncosine-corrected selenium barrier layer photovoltaic cell housed in a waterproof case. The photocell was a 45-mm type B Megatron, mounted and potted. The spectral response was modified using Rank Strand cinemoid jellatin filters, numbers 17 and 54, following the method of Dawson. ${ }^{27}$

\section{G. Photographic equipment}

Real-time viewing of the experimental cage and krill was obtained with a low-light-level silicon-intensified-target (SIT) underwater television camera. Television images were displayed, recorded, and replayed through programmable videotape units.

A stereoscopic still camera system was also suspended with the television camera. However, for a variety of reasons and in spite of arduous, if Sisyphean, labors, the system provided few data and none on the particular acoustically measured krill.

\section{H. Apparatus for biological and sound-speed measurements}

Apparatus sufficient for making ordinary biological measurements of krill was available. This included a precision balance, density bottles, graduated cylinders, measuring boards, scalpels, pincers and like tools for examining, manipulating, and measuring individual specimens.

The sound-speed-measuring apparatus is described in Ref. 28. In brief, it included a T-shaped tube, used in the inverted position, with a $500-\mathrm{kHz}-$ resonant acoustic transducer mounted at each end; electronics for controlling the pulsing and reception; a two-channel $100-\mathrm{MHz}$ bandwidth oscilloscope for displaying the transmitted signal and independent, adjustable-length square wave; and a multimeter for measuring resistance to four significant figures. A thermometer accurate to $\pm 0.05^{\circ} \mathrm{C}$ over the approximate range $[0,30]^{\circ} \mathrm{C}$ accompanied the apparatus for use in monitoring the measurement temperature.

\section{METHODS}

Measurements of echo energy were made from encaged krill, empty cages, calibration spheres, and integration volume without cage. Each series of echo energy measurements on a given object is referred to as an event. Measurements of length, maturity stage, density, and sound speed were made on samples of krill removed from the cage at the end of each event. The proportion of analyzed krill varied from $25 \%$ to $100 \%$ of the encaged number.

\section{A. Echo sounder operation}

The acoustic measurements were generally made in the same way. Standard settings were used on the SIMRAD EK-400 echo sounder. The time-varied-gain (TVG) function was the " $20 \log r$ " type. The pulse repetition frequency was a constant 50 pulses/min, with alternating transmissions at 38 and $120 \mathrm{kHz}$. The nominal pulse duration in the measurements considered here was $1.00 \mathrm{~ms}$. Attenuator and gain settings were adjusted depending on the measurement object.

\section{B. Echo integration}

Integration of the squared received voltage was performed over the full range interval corresponding to echoes from the cage. This was $[6.0,8.0] \mathrm{m}$ for nearly all measurements. The exceptional cases with krill involved event numbers 54 and 55, when the cage was lowered $1 \mathrm{~m}$, for which the integration interval was $[7.0,9.0] \mathrm{m}$.

Results of echo integration were summed over intervals corresponding to either 0.2 or 1.0 nautical miles at a simulated vessel speed of $10 \mathrm{kn}$, hence for 1.2 or $6 \mathrm{~min}$, respectively. The cumulative numbers were divided by the interval distance and presented as estimates of mean volume backscattering strength in decibels. ${ }^{24}$ These values, together with those from other integration intervals, were displayed on a screen and stored on a British Antarctic Survey data logger at the end of each integration period. The variability in echo integration result from ping to ping could not be studied for want of sufficient data-logging capacity at the measurement site.

\section{Calibration}

On-axis calibration with standard spheres ${ }^{29}$ was performed throughout the experiment as often as circumstances allowed. In the absence of the cage, the sphere was lowered to a position intended to be at the center of the cage. The echo sounder and integrator were then operated as during the cage measurements. Adjustment of the attenuator and gain settings during several calibration events established the relative accuracy of these.

To supplement the on-axis calibrations at cage depth, a tungsten carbide sphere was routinely suspended at a fixed position below the transducers, but outside of the cage integration interval. This provided a ready means of monitoring equipment performance. 


\section{Empty cage and volume reverberation measurements}

Measurements on empty cages were also performed as circumstances allowed, but again covering the entire period of the krill measurements. Measurement of the water volume without cage, but with rig in place, established the general lowness of the volume reverberation. Continual monitoring with the underwater television camera confirmed the general absence of visible extraneous scatterers near the cage. The exceptions were provided by several occurrences of krill swarms in Stromness harbor, occasional occurrences of acoustically inevident ctenophores, and rare, brief visits by Gentoo penguins (Pygoscelis papus) or the odd blue-eyed shag (Phalacrocorax atriceps).

\section{E. Beam-pattern mapping}

A tungsten carbide sphere was also used to map the transducer beam patterns. The adopted procedure was that due to Simmonds, ${ }^{30}$ although with a deliberately lesser degree of automation.

\section{F. Environmental monitoring}

The CTD-sonde was suspended at the nominal $15-\mathrm{m}$ depth of the cage, but from the second moonpool, which was reserved for such measurements. When operating, both temperature and salinity were measured at 15 -s intervals but logged every $2 \mathrm{~min}$ throughout the day. In addition, the light intensity at the same depth was measured and recorded at 2min intervals.

\section{G. Krill measurement}

Immediately prior to an event, krill were removed from the holding pen with a small dip net, with c. $100-\mathrm{cm}^{2}$ opening, and counted into a 100 -liter tub half-filled with surface seawater. After reaching the predetermined number, more or less, the tub was ferried to the measurement raft. Here, after raising the cage to near the surface, the krill were syphoned into it through a small slit in the top panel. Handling of the krill was thus minimal, and their apparently vigorous condition was continually confirmed by television. Krill were removed from the cage through a slit in the bottom panel. Both slits were secured by threading monofilament nylon through reinforced meshes on the sides of the opening.

Upon completing an encaged-aggregation event, the krill were transferred to the laboratory in a tub with seawater. On average, about half of the krill continued swimming vigorously, and nearly all showed signs of life, although the overall condition did vary considerably from event to event.

The sound speed in samples was measured according to the time-of-flight method. ${ }^{28}$ The salinity of the seawater was measured, and the temperature was monitored continually during the sound-speed measurements.

Following each sound-speed experiment, the total length, from the anterior margin of the eye to the tip of the telson, rounded down to the nearest millimeter, was measured for at least $100 \mathrm{krill}$. In addition, the wet weight of this subsample of krill and the wet weight of all the krill in the sound-speed experiment were measured to within $\pm 1 \mathrm{mg}$. The density of small batches of krill of similar size were estimated using a density-bottle technique. Measurements of total length were also made sometimes on subsamples of krill removed from the cage but not used in sound-speed experiments. The number and wet weight of all krill removed from the cage were obtained by enumerating and weighing any remaining krill and addition of all subsamples.

The total number of krill removed from the cage was generally less than the starting number by a few percent, presumably owing to cannibalism. In the worst case, event number 36 , the initial number was reduced by $7 \%$, but over a 42-h period. In another case, event number 20, the number apparently increased by two specimens, believed due to miscounting or possibly entrapment by the cage during intense swarming observed in the harbor.

\section{DATA ANALYSIS}

The first step in the analysis of encaged-aggregation data was to decide which data were usable. Whole events with encaged krill had to be purged for the following reasons: (1) early use of wrong limits for the integration interval, (2) distortion of the cage, with displacement from the usual position in the beam, due to entangling of the cage suspension lines, and (3) damage of the cage, with mass escape of krill, owing to a presumed collision or attack by a seal. Half of the data from another event, number 28 , had to be purged because of severing of the lifting rope to the underwater rig in heavy-swell conditions.

Data in the remaining events were purged very cautiously for the following reasons: (1) event start-up effects, always of short duration, (2) observed or presumed interference by extraneous scatterers such as fish, penguins, or krill swarms in the harbor attracted deliberately to the measurement raft by using underwater lights at night, (3) radio interference with the receivers during arrival of a yacht under motor power, and (4) trial use of different echo sounder settings or transducer beamwidths. For some events no data were purged, and for no event was more than $15 \%$ of the data purged, except for the fourth cause.

In order to extract target strengths or backscattering cross sections from the echo integrator data, the mean volume backscattering strengths had to be reduced. This entailed a number of analyses.

(1) Conversion factors. To express the echo integrator data as absolute quantities, the calibration data were reduced. Upon combining, the following factors were derived for adding to the logarithmic SIMRAD QD units: -42.3 and $-31.1 \mathrm{~dB}$ for the data at 38 and $120 \mathrm{kHz}$, respectively. The total range of variation of these factors was $\pm 0.4 \mathrm{~dB}$ each.

(2) Time-varied-gain (TVG) correction factors. Several errors were incurred by the use of TVG in the receiver. One is due to the rather short target range, 6-7 m, for which the pulse length, $1.47 \mathrm{~m}$, is not negligibly small. The other error is due to the distributed nature of the cage and krill 
aggregation, which is to be compared to the compactness of a calibration sphere. The extent of the cage, and krill aggregation too if so dispersed, was $0.5 \mathrm{~m}$ vertically and slightly more aslant as viewed from the transducer. For the particular " $20 \log r$ " TVG used throughout the measurements, the resulting correction factors are $-0.4 \mathrm{~dB}$ for the cage at nominal 6-m range and $1.0 \mathrm{~dB}$ for the cage at nominal $7-\mathrm{m}$ range. These figures apply at both frequencies. Estimated errors of the correction factor due to uncertainty in the precise target ranges, expressed through the standard deviations, are \pm 0.2 and $\pm 0.1 \mathrm{~dB}$ at the respective 6 - and $7-\mathrm{m}$ ranges.

(3) Beam pattern compensation factors. The transducer beams were nonuniform across the cage and unaligned with the cage axis. Each beam center was inferred from the respective beam-pattern-mapping data by a least-squares procedure based on comparison with the theoretical beam patterns. Integration of the squared beam pattern over the cage cross section and normalizing this to the solid angle formed by the cage yields compensation factors of 0.9 and $0.7 \mathrm{~dB}$ at 38 and $120 \mathrm{kHz}$, respectively, for the cage at nominal 6-m depth, and 0.7 and $0.6 \mathrm{~dB}$ for the cage at nominal 7 $m$ depth. Estimated errors of the compensation factors due to uncertainty in both measured and computed beam patterns are $\pm 0.1 \mathrm{~dB}$.

Application of these three factors to the echo integrator data produces a series of numbers for the equivalent target strength of the krill and cage together. This is alternatively expressed through the backscattering cross section $\sigma$ by the standard relation, TS $=10 \log \sigma / 4 \pi$, with use of SI units.

The cage contribution can be removed in two different ways. (1) Because of the availability of empty-cage measurements, these can be averaged and the mean contribution can be subtracted in the appropriate intensity domain. ${ }^{22}$ The effective cage target strengths in uncompensated echo integrator units are $-20.3 \pm 1.2 \mathrm{~dB}$ and $-19.3 \pm 1.4 \mathrm{~dB}$ at 38 and $120 \mathrm{kHz}$, respectively. Following subtraction, averaging yields the mean backscattering cross section per krill. (2) The effective cage contribution can also be inferred by regressing the equivalent backscattering cross section of cage and krill on the number of encaged krill. The intercept is then the cage contribution, and the slope or regression coefficient is the mean backscattering cross section of a single krill. Both methods of compensating for the cage contribution are used.

Analysis of the sound-speed data is described in Ref. 28.

\section{RESULTS}

Summary results of encaged-aggregation events with usable krill data are presented in Table I. The mean target strengths, denoted $\overline{\mathrm{TS}}$, are determined in the usual fashion. First, the mean backscattering cross section $\bar{\sigma}$ is computed; then the mean target strength is derived from the definition $\overline{\mathrm{TS}}=10 \log \sigma / 4 \pi$.

The mean krill target strength, denoted TS $_{1 \text { krill }}$ in Table I, is determined by the first method of removing the cage contribution, viz., by subtracting the mean empty-cage contribution in the intensity domain. The missing datum, for event number 54 at $120 \mathrm{kHz}$, reveals a flaw in the method, if not in the data. Here the actual cage contribution must be less than the number assumed for it. Indeed, the echo strength of cage and krill together is less than the mean cage contribution. Furthermore, the equivalent target strength at $38 \mathrm{kHz}$ of cage and krill together for event number 54 is greater than that for event number 55, although the second has twice the number of krill of the first. Given the proximity of these events, their data are not used in the analyses reported in Table II.

The result of averaging the single-krill backscattering cross sections corresponding to the respective values of target strength in Table I is shown in the "subtraction" row of

TABLE I. Summary of measured krill target strengths by event. The mean number of krill is the arithmetic mean of the numbers at the start and end of each event. The standard deviation in length distribution is denoted $\Delta l$, and the respective sample size $n_{s}$. Each acoustic sample is the result of averaging over a 6 min interval at the effective PRF of 25 pulses/min. The mean single-krill target strength TS $_{1 \text { krill }}$ is derived according to the subtraction method.

\begin{tabular}{|c|c|c|c|c|c|c|c|c|c|c|c|c|}
\hline \multirow{3}{*}{$\begin{array}{c}\text { Event } \\
\text { No. }\end{array}$} & \multirow[b]{3}{*}{ Duration } & \multirow{3}{*}{$\begin{array}{r}\text { Mean no. } \\
\text { krill } \\
N\end{array}$} & \multirow{2}{*}{\multicolumn{3}{|c|}{ Krill lengths (mm) }} & & \multicolumn{3}{|c|}{$\mathrm{TS}(\mathrm{dB})$ at $38 \mathrm{kHz}$} & \multicolumn{3}{|c|}{$\mathrm{TS}(\mathrm{dB})$ at $120 \mathrm{kHz}$} \\
\hline & & & & & & & & TS & & & TS & \\
\hline & & & $\overline{l^{2}} 1 / 2$ & $\bar{l}$ & $\Delta l$ & $n_{\mathrm{s}}$ & $\mathrm{TS}_{1 \mathrm{krlll}}$ & krill & $n_{s}$ & TS $_{1 \text { krill }}$ & krill & $n_{s}$ \\
\hline 17 & $16 \mathrm{~h} 46 \mathrm{~min}$ & 496 & 39.7 & 39.4 & 4.4 & 458 & -84.1 & -55.9 & 159 & -75.9 & -46.5 & 159 \\
\hline 19 & $15 \mathrm{~h} 22 \mathrm{~min}$ & 246 & 32.0 & 31.8 & 3.4 & 100 & -82.6 & -57.1 & 132 & -74.5 & -47.3 & 132 \\
\hline 20 & $23 \mathrm{~h} 16 \mathrm{~min}$ & 351 & 34.2 & 33.8 & 4.8 & 100 & -82.8 & -56.1 & 206 & -76.2 & -47.4 & 206 \\
\hline 26 & $23 \mathrm{~h} 1 \mathrm{~min}$ & 752 & 31.0 & 30.9 & 2.4 & 300 & -87.8 & -57.3 & 202 & -77.3 & -46.2 & 202 \\
\hline 28 & $38 \mathrm{~h} 38 \mathrm{~min}$ & 390 & 30.2 & 30.1 & 2.2 & 100 & -83.6 & -56.4 & 189 & -74.6 & -46.3 & 189 \\
\hline 30 & $40 \mathrm{~h} 13 \mathrm{~min}$ & 458 & 35.4 & 35.3 & 3.2 & 200 & -85.1 & -56.9 & 376 & -74.8 & -46.0 & 376 \\
\hline 36 & $42 \mathrm{~h} 31 \mathrm{~min}$ & 1368 & 32.3 & 32.2 & 3.0 & 500 & -85.5 & -53.5 & 424 & -75.6 & -43.2 & 424 \\
\hline 37 & $18 \mathrm{~h} 13 \mathrm{~min}$ & 787 & 31.3 & 31.2 & 3.2 & 200 & -88.0 & -57.3 & 180 & -76.5 & -45.7 & 180 \\
\hline 43 & $37 \mathrm{~h} 3 \mathrm{~min}$ & 398 & 33.6 & 33.5 & 2.8 & 200 & -87.6 & -58.8 & 164 & -77.0 & -47.5 & 358 \\
\hline 47 & $64 \mathrm{~h} 41 \mathrm{~min}$ & 1593 & 32.9 & 32.8 & 2.9 & 397 & -89.1 & -55.9 & 318 & -79.7 & -45.7 & 298 \\
\hline 50 & $42 \mathrm{~h} 36 \mathrm{~min}$ & 850 & 31.6 & 31.5 & 2.7 & 200 & -86.6 & -56.1 & 232 & -78.0 & -46.3 & 411 \\
\hline 52 & $65 \mathrm{~h} 5 \mathrm{~min}$ & 816 & 38.6 & 38.4 & 3.8 & 200 & -84.2 & -54.3 & 632 & -75.4 & -44.8 & 632 \\
\hline 54 & $62 \mathrm{~h} 44 \mathrm{~min}$ & 394 & 31.7 & 31.5 & 3.7 & 200 & -86.9 & -58.4 & 619 & .. & -50.2 & 619 \\
\hline 55 & $46 \mathrm{~h} 7 \mathrm{~min}$ & 794 & 31.5 & 31.3 & 3.3 & 200 & -88.3 & -58.7 & 459 & -80.7 & -48.6 & 461 \\
\hline
\end{tabular}


TABLE II. Summary results for each of two methods of removing the empty-cage contribution, based on the data in Table I, exclusive of those for event numbers 54 and 55 . The quantities $\mathrm{TS}_{1}$ and $\mathrm{TS}_{2}$ are defined in the text; they correspond to the range of variation in $\overline{\mathrm{TS}}$ as defined by \pm one standard deviation in $\sigma$.

\begin{tabular}{|c|c|c|c|c|c|c|c|c|c|c|}
\hline \multirow[b]{2}{*}{ Method } & \multicolumn{5}{|c|}{$38 \mathrm{kHz}$} & \multicolumn{5}{|c|}{$120 \mathrm{kHz}$} \\
\hline & $\bar{\sigma}\left(\mathrm{mm}^{2}\right)$ & $\operatorname{cv}(\%)$ & $\overline{\mathrm{TS}}$ & $\mathrm{TS}_{1}$ & $\mathrm{TS}_{2}$ & $\bar{\sigma}\left(\mathrm{mm}^{2}\right)$ & $\operatorname{cv}(\%)$ & $\overline{\mathbf{T S}}$ & $\mathrm{TS}_{1}$ & $\mathrm{TS}_{2}$ \\
\hline Subtraction & 0.039 & 47 & -85.1 & -87.9 & -83.4 & 0.311 & 31 & -76.1 & -77.7 & -74.9 \\
\hline Regression & 0.015 & 46 & -89.4 & -92.1 & -87.7 & 0.173 & 33 & -78.6 & -80.3 & -77.4 \\
\hline
\end{tabular}

Table II. The coefficient of variation of $\bar{\sigma}$ is included together with the mean target strength. The additional quantities are defined thus: $\mathrm{TS}_{1}=10 \log (\bar{\sigma}-\Delta \sigma) / 4 \pi$ and $\mathrm{TS}_{2}=10$ $\times \log (\bar{\sigma}+\Delta \sigma) / 4 \pi$.

The equivalent mean target strength of cage and krill together is denoted $\mathbf{T S}_{\text {cage }}+N$ krill in Table I. Regression of the corresponding values of backscattering cross section on $N$ allows derivation of $\bar{\sigma}$ for one krill through the regression coefficient. This is shown in the "regression" row in Table II. The coefficient of variation in this case is formed by expressing the standard error of the regression coefficient as a percentage of the regression coefficient, namely $\bar{\sigma}$.

The analyses reported in Table II have been repeated for another subset of the data in Table I. This excludes the data with rms lengths greater than $35.0 \mathrm{~mm}$. The results are not significantly different from their antecedents. Specifically, TS decreases by $0.2 \mathrm{~dB}$ at each frequency for the subtraction method, while remaining unchanged for the regression method. The rms lengths for the two subsets are 33.7 and $32.1 \mathrm{~mm}$, respectively.

\section{MODEL COMPUTATIONS}

Measurement of the density, sound speed, and length distribution of fresh samples of krill from the encaged-aggregation events provides sufficient data for the simplest model computations. Comparison of the measured physical properties of the animal with the respective properties of seawater determines the following contrasts: for density, $1.0357 \pm 0.0067$, and for sound speed, $1.0279 \pm 0.0024$, assuming negligible dispersion. ${ }^{28}$

The model exercised here is that of the fluid sphere ${ }^{31}$ in its so-called high-pass form, ${ }^{32}$ but as stated by .Greenlaw. ${ }^{33}$ Accordingly, the backscattering cross section $\sigma$ has the following expression:

$$
\sigma=4 \pi a^{2} \frac{2(k a)^{4}}{2+3(k a)^{4}}\left|\frac{1-g h^{2}}{3 g h^{2}}+\frac{1-g}{1+2 g}\right|^{2},
$$

where $a$ is the equivalent sphere radius (ESR), $k$ is the acoustic wavenumber, $g$ is the density contrast, and $h$ is the sound-speed contrast. The ESR is computed from the following empirical expression for the single-animal volume $v$ in cubic centimeters:

$$
v=0.939 m-0.003,
$$

where $m$ is the mass in grams, ${ }^{34}$

$$
m=9.60 \times 10^{-6} l^{2.94},
$$

and $l$ is the total krill length in millimeters. ${ }^{35}$ Because each measured sample consisted of a number of specimens of varying lengths, $\sigma$ was averaged over the frequency distribution of lengths, $n(l)$ :

$$
\bar{\sigma}=\sum_{l} n(l) \sigma(l) \quad \sum_{l} n(l)
$$

To compute $k$ in Eq. (1), the medium sound-speed is assumed to be $1457 \mathrm{~m} / \mathrm{s}$.

In order to express the uncertainties associated with the estimates of density and sound-speed contrasts, $\bar{\sigma}$ was also computed at each of the first standard deviations. Denoting the nominal values by $g_{0}=1.0357$ and $h_{0}=1.0279$, the nominal averaged backscattering cross section $\bar{\sigma}_{0}$ is expressed thus:

$$
\bar{\sigma}_{0}=\bar{\sigma}\left(g_{0}, h_{0}\right) .
$$

The estimated first-standard-deviation values $\bar{\sigma}_{ \pm}$are computed as the geometric mean of the respective quantities, that is,

$$
\bar{\sigma}_{ \pm}=\left[\bar{\sigma}\left(g_{0} \pm \Delta g, h_{0}\right) \bar{\sigma}\left(g_{0}, h_{0} \pm \Delta h\right)\right]^{1 / 2} .
$$

The several estimates have been computed for each length distribution and echo sounder frequency characterizing the events listed in Table I. They are presented in Table III through the corresponding values of target strength, denoted $\mathrm{TS}_{0}$ and $\overline{\mathrm{TS}}_{ \pm}$, where, as before, $\overline{\mathrm{TS}}=10 \log \bar{\sigma} / 4 \pi$, with $\bar{\sigma}$ expressed in units of square meters.

\section{DISCUSSION}

\section{A. Measurements}

According to the post-FIBEX target strength-length relations, ${ }^{11,12}$ the mean target strength of a krill of $33.7-\mathrm{mm}$ length is $-60.1 \mathrm{~dB}$ at $50 \mathrm{kHz}$ and $-65.3 \mathrm{~dB}$ at $120 \mathrm{kHz}$. The new data, based on measurements at 38 and $120 \mathrm{kHz}$, are seen from Tables I and II to be substantially lower, notwithstanding the difficulty of comparing data at the lower frequencies, 38 and $50 \mathrm{kHz}$. The mean target strength of krill of mean length $33.7 \mathrm{~mm}$ was observed to be in the approximate range $[-89,-85] \mathrm{dB}$ at $38 \mathrm{kHz}$ and $[-79,-76]$ $\mathrm{dB}$ at $120 \mathrm{kHz}$.

The new measurements also show a high degree of variability. The authors cannot explain this, but they can speculate on causes. 
TABLE III. Averaged theoretical target strengths derived from Eqs. (5) and (6) for the length distribution of each encaged-aggregation event listed in Table I. Values of $k a$ are computed with respect to the mean length $\bar{l}$.

\begin{tabular}{|c|c|c|c|c|c|c|c|c|c|}
\hline \multirow{2}{*}{$\begin{array}{c}\text { Event } \\
\text { no. }\end{array}$} & \multirow[b]{2}{*}{$\bar{l}(\mathrm{~mm})$} & \multicolumn{4}{|c|}{$38 \mathrm{kHz}$} & \multicolumn{4}{|c|}{$120 \mathrm{kHz}$} \\
\hline & & $k a$ & $\overline{\mathrm{TS}}_{-}$ & $\overline{\mathrm{TS}}_{\mathrm{o}}$ & $\overline{\mathbf{T S}}_{+}$ & $k a$ & $\overline{\mathrm{TS}}_{-}$ & $\overline{\mathbf{T S}}_{0}$ & $\overline{\mathbf{T S}}_{+}$ \\
\hline 17 & 39.4 & 0.8 & -81.0 & -80.4 & -79.8 & 2.4 & -76.8 & -76.2 & -75.6 \\
\hline 19 & 31.8 & 0.6 & -85.4 & -84.8 & -84.2 & 2.0 & -78.7 & -78.1 & -77.5 \\
\hline 20 & 33.8 & 0.7 & -83.8 & -83.2 & -82.6 & 2.1 & -78.1 & -77.5 & -76.9 \\
\hline 26 & 30.9 & 0.6 & -86.2 & -85.6 & -85.1 & 1.9 & -79.0 & -78.4 & -77.9 \\
\hline 28 & 30.1 & 0.6 & -86.8 & -86.2 & -85.6 & 1.9 & -79.3 & -78.6 & -78.0 \\
\hline 30 & 35.3 & 0.7 & -83.3 & -82.7 & -82.1 & 2.2 & -77.8 & -77.2 & -76.6 \\
\hline 36 & 32.2 & 0.6 & -85.2 & -84.6 & -84.1 & 2.0 & -78.6 & -78.0 & -77.4 \\
\hline 37 & 31.2 & 0.6 & -85.9 & -85.2 & -84.6 & 1.9 & -78.9 & -78.3 & -77.7 \\
\hline 43 & 33.5 & 0.7 & -84.4 & -83.8 & -83.2 & 2.1 & -78.3 & -77.7 & -77.1 \\
\hline 47 & 32.8 & 0.7 & -84.8 & -84.2 & -83.6 & 2.1 & -78.5 & -77.8 & -77.2 \\
\hline 50 & 31.5 & 0.6 & -85.8 & -85.1 & -84.6 & 2.0 & -78.8 & -78.2 & -77.6 \\
\hline 52 & 38.4 & 0.8 & -81.6 & -81.0 & -80.4 & 2.4 & -77.1 & -76.4 & -75.9 \\
\hline 54 & 31.5 & 0.6 & -85.5 & -84.9 & -84.4 & 2.0 & -78.8 & -78.2 & -77.6 \\
\hline 55 & 31.3 & 0.6 & -85.7 & -85.1 & -84.6 & 2.0 & -78.9 & -78.3 & -77.7 \\
\hline
\end{tabular}

Measurement error. The working conditions were often difficult. The effects of wind, swell, and underwater currents on alignment of transducers and cage are unknown. Observation of the echo data during its collection never suggested any large effect due to surface conditions, but the kind of control measurements necessary for quantifying the effects were never carried out, for simple want of time. The effect of the cage on the echo energy was, for the same reason, insufficiently studied. The fact that the echo energy from cage-andkrill system at $120 \mathrm{kHz}$ in event 54 was less than the average empty-cage echo energy indicates in dramatic fashion that there was an effect. The underlying cause may be changes in the acoustic properties of the plastic netting.

Variable behavior. Videotape records of krill behavior show no conspicuous differences in aggregation characteristics from event to event, although a spectrum of behavior modes-from dense swarming to relative dispersion-was observed for each. Because extinction could not have been measured for the particular numbers of krill and cage geometry, the acoustically significant part of behavior is that due to orientation, in particular, that due to the animal's tilt relative to the horizontal plane. ${ }^{7,20}$ In fact, for the present sizes and frequencies, the effect could easily have been substantial. ${ }^{13}$ It was the authors' firm intention to collect data on the orientation distribution of the encaged krill. The stereoscopic camera system failed utterly, however, so this must remain one of the major shortcomings of the experiment.

Variable biology. The krill were obtained by trawling at sea or by dipnetting in Stromness harbor. For operational reasons, they could not be segregated. In addition, the supplies were supplemented at irregular intervals. Selection of krill for any particular encaged-aggregation event proceeded by catching the desired number of swimming, apparently healthy, specimens from one of the four holding pens. It is entirely possible, if not likely, that the biological state of penned krill changed in the course of the experiment. It is even possible that the condition of krill changed in the course of an event. Measurements of sound speed show consider- able variability from event to event and from sample to sample, but this does not correlate with the variation in target strength. By itself, variation in sound speed cannot account for the observed variability in target strength.

Notwithstanding the expressed doubts, the overall condition of the krill seemed to be excellent throughout the experiment. Quite often the krill were observed to be grazing on algae growing on the walls of the holding pens or grazing in the middle of the cage. Many samples of krill examined at the conclusion of the encaged-aggregation events showed bright green alimentary canals, a sign of a well-fed state.

Observations of behavior, by underwater television camera, also support a belief in the good quality of the presented data. At times, the krill were observed swimming together as one, all parallel. Often the krill gathered together in dense clumps or knots, occupying a fraction, say from $1 / 4$ to $1 / 8$ or less, of the cage volume. That is, swarming behavior akin to that observed by underwater divers in the middle of naturally occurring swarms ${ }^{36}$ was observed. At other times, the krill were spread out through the cage volume. Sometimes distinct effects of encagement were evident, but it is premature to say whether this is reflected in the acoustic record.

Some systematics of the cage behavior were aggregation at day and dispersion at night. The krill were generally swimming. Modifications in behavior were observed due to weather and to the cage itself.

\section{B. Model computations}

The simplest model was examined first, once the data on density and sound-speed contrasts were analyzed. The fluidsphere model, as given by Greenlaw, ${ }^{33}$ with the averaging indicated in Eq. (4), yielded the estimates shown in Table III. These are compared with the corresponding empirical values TS $_{1 \text { krill }}$ in Table $I$ and in Fig. 1. Several trends are seen: The theoretical values are slightly higher than the empirical ones at $38 \mathrm{kHz}$, but slightly lower at $120 \mathrm{kHz}$. In addition, the range of variation in measured data is generally 
larger than that estimated according to the simple model. Given the vagaries of experimentation, with incomplete specification of animal properties and physical configurations, and use of a very approximate scattering model, better agreement can hardly be expected. It is assuredly best to postpone further speculation, at least until the kinds of data required for use with the new and increasingly sophisticated models of Stanton ${ }^{37-39}$ are available, e.g., those on orientation, shape, flexure, and physical properties.

Nonetheless, within present bounds, the authors believe that the measurements and fluid-sphere model are consistent. This observation supports, and perhaps supplements as well, one of Holliday and Pieper's conclusions from an experimental study on zooplankton reported in 1980 (Ref. 40). In this, the fluid-sphere model was found to be adequate to explain the frequency dependence of data with $k a$ less than about three. This is precisely the condition on mean $k a$ for this study, as seen from Table III. The present krill measurements are, of course, absolute, as are the model computations.

\section{Future}

The authors would remedy a number of shortcomings in their execution of the krill target strength experiment. Chief among these would be the collection of data on orientation. The empty cage would be measured acoustically more often, and, in general, a greater effort would be made to tie environmental factors to the record of variation in krill target strength.

Given a greater range of animal sizes, the target strength

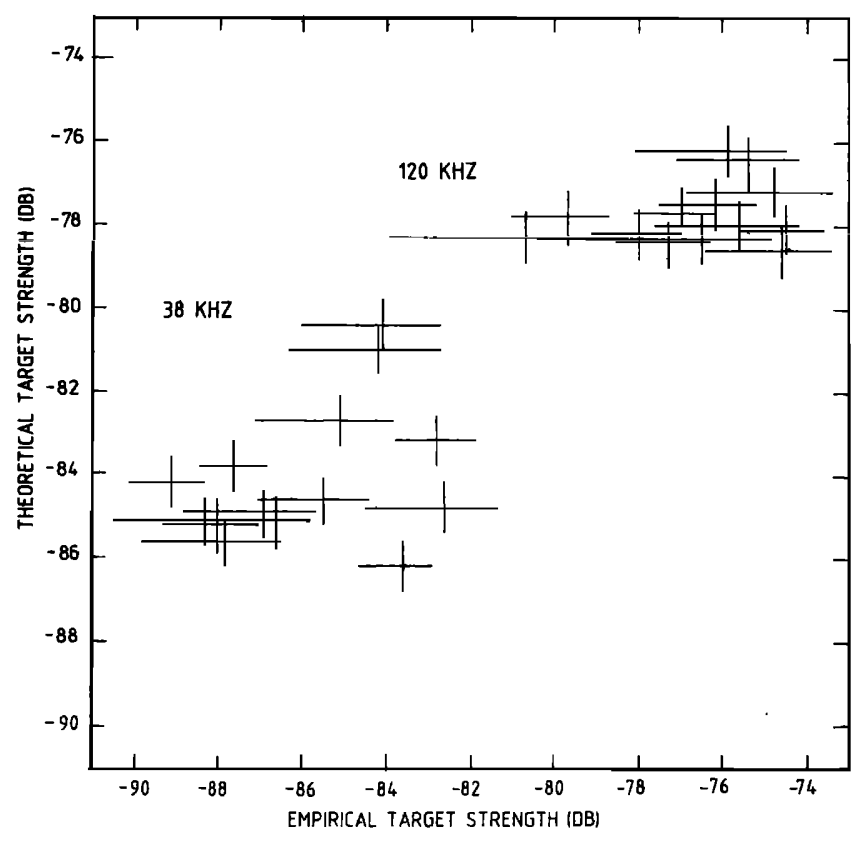

FIG. 1. Comparison of empirically and theoretically determined values of target strength, with means derived from, respectively, Tables I and III. The degree of variation is indicated through bars defined as \pm one standard deviation. The contiguous data in the upper right corner apply at $120 \mathrm{kHz}$; the others apply at $38 \mathrm{kHz}$. would be measured with the aim of specifying some of its biological and physical dependences. These would include biochemical composition and quantified morphology. Measurement of a wider range of sizes and states of krill would therefore be attempted, particularly with gravid females, which eluded the experimenters in the present study.

Any new acoustic measurements on krill would be performed with new echo sounding and integrating equipment. The new SIMRAD EK5OO scientific echo sounding system ${ }^{41,42}$ would be a prime candidate for a number of reasons. It would enable three different transducers to be operated simultaneously. In a suitable environment, when the krill are sufficiently dispersed, single-animal target strengths could be measured because of incorporation of the split-beam function in this instrument. The nominal dynamic range of 160 $\mathrm{dB}$ would also allow the range of interesting objects from single krill to calibration sphere to bottom, for example, to be measured without the need to change instrument settings.

The new Bergen Echo Integrator ${ }^{43,44}$ would also be used, for flexibility in display or presentation of the data on a UNIX-based workstation, and for ease of storage of the three-transducer data with maximal resolution for each and every ping. Operator-controlled post-processing of the data would considerably enhance the analysis process, while providing a backup to the echo integration function of the SIMRAD EK500 echo sounder.

Application of the same instruments to naturally occurring swarms is inevitable. The value or necessity of supporting these through additional controlled measurement will be defined by the aim of such application, or more specifically, the required degrees of precision and accuracy.

\section{SUMMARY CONCLUSIONS}

The target strengths of krill at 38 and $120 \mathrm{kHz}$ are substantially lower than the post-FIBEX values. The reported measurements and fluid-sphere model are consistent. Use of the model with data on density and sound-speed contrasts can extend the present work to other sizes and frequencies, at least for $k a$ values less than about three.

\section{ACKNOWLEDGMENTS}

Captain John Cole and fellow officers and crew of RRS BRANSFIELD are thanked for logistics support. Captain Malcolm Phelps and fellow officers and crew of RRS JoHN BisCOE are thanked for both logistics support and assistance during the krill-catching cruises. William Graham is thanked for technical assistance on all electronics matters. Travel support of one of the authors (KF) by the Norwegian Council for Fisheries Research is acknowledged.

'R. M. Laws, "The ecology of the Southern Ocean," Am. Sci. 73, 26-40 (1985).

${ }^{2}$ H.-P. Marschall, "The overwintering strategy of Antarctic krill under the pack-ice of the Weddell Sea," Polar Biol. 9, 129-135 (1988).

${ }^{3}$ I. Everson, "The living resources of the Southern Ocean," FAO GLO/SO/77/1, Rome (1977), 155 pp.

${ }^{4} \mathrm{~T}$. Doi, "Target strength, distribution pattern and abundance of krill Euphausia superba in the Antarctic observed by Kaiyo-Maru in 1981 season," Contribution No. 26, Symposium on Fisheries Acoustics, Bergen, Norway, 21-24 June 1982. 
${ }^{5}$ V. A. Protaschuk and T. A. Lukashova, "Determination of Antarctic krill acoustic back scattering cross section," Contribution No. 66, Symposium on Fisheries Acoustics, Bergen, Norway, 21-24 June 1982.

'J. A. Kalinowski, A. Dyka, and L. Kilian, "The target strength of krill," Polish Polar Res. 1, 147-153 (1980).

${ }^{7}$ C. F. Greenlaw, "Backscattering spectra of preserved zooplankton," J. Acoust. Soc. Am. 62, 44-52 (1977).

${ }^{8}$ V. G. Samovolkin, "Instrumentation and method of investigating the backscattering of ultrasonic waves by biological subjects in water," Oceanology 14, 149-152 (1974).

${ }^{9}$ V. G. Samovolkin, "Backward scattering of ultrasonic waves by shrimps," Oceanology 20, 1015-1020 (1980).

${ }^{10}$ A. Kristensen, "Acoustic classification of zooplankton," Ph.D. thesis, The Norwegian Institute of Technology, Trondheim, Norway (1983), 107 pp.

${ }^{11}$ Report on Post-FIBEX Acoustic Workshop, Frankfurt, 3-14 September 1984, BIOMASS Rep. Ser. 40, (1986), 126 pp.

${ }^{12} I$. Everson, "Krill target strength, current status," SC-CAMLRVI/BG/9 (1987), 14 pp.

${ }^{13}$ D. D. Sameoto, "Quantitative measurements of euphausiids using a 120kHz sounder and their in situ orientation," Can. J. Fish. Aquat. Sci. 37, 693-702 (1980).

${ }^{14}$ J. W. Køgeler, S. Falk-Petersen, Å. Kristensen, F. Pettersen, and J. Dalen, "Density- and sound speed contrasts in sub-Arctic zooplankton," Polar Biol. 7, 231-235 (1987).

${ }^{15}$ N. Roschke, "Variabilität des Fett- und Proteingehalts beim Krill ( $E u$ phausia superba Dana)," Meeresforsch. 26, 217-221 (1977/78).

${ }^{16} \mathrm{~A}$. Clarke, "The biochemical composition of krill, Euphausia superba Dana, from South Georgia,”' J. Exp. Mar. Biol. Ecol. 43, 221-236 (1980).

${ }^{17}$ O. Saether, T. E. Ellingsen, and V. Mohr, "The distribution of lipid in the tissues of Antarctic krill, Euphausia superba," Comp. Biochem. Physiol. 81B, 609-614 (1985).

${ }^{18} \mathrm{C}$. F. Greenlaw and R. K. Johnson, "Physical and acoustical properties of zooplankton,” J. Acoust. Soc. Am. 72, 1706-1710 (1982).

${ }^{19} \mathrm{C}$. F. Greenlaw, R. K. Johnson, and T. Pommeranz, "Volume scattering strength predictions for Antarctic krill (Euphausia superba Dana)," Meeresforsch. 28, 48-55 (1980).

${ }^{20} \mathrm{~J}$. Dalen and A. Kristensen, "Measurements of target strength and spatial orientation of euphausiids (krill)," Coun. Meet. Int. Coun. Explor. Sea 1981/B:6, Copenhagen.

${ }^{21} \mathrm{~K}$. G. Foote, "A critique of Goddard and Welsby's paper 'The acoustic target strength of live fish", J. Cons. Int. Explor. Mer 42, 212-220 (1986).

${ }^{22}$ K. G. Foote, "Linearity of fisheries acoustics, with addition theorems," J. Acoust. Soc. Am. 73, 1932-1940 (1983).

${ }^{23}$ R. Brede, "SIMRAD EK-400 scientific echo sounder," FAO Fish. Circ. 778, 44-56 (1984).

${ }^{24}$ R. Brede, "SIMRAD QD echo integrator," FAO Fish. Circ. 778, 100-106 (1984).
${ }^{25}$ K. G. Foote, "Optimizing copper spheres for precision calibration of hydroacoustic equipment," J. Acoust. Soc. Am. 71, 742-747 (1982).

${ }^{26}$ D. N. MacLennan and F. Armstrong, "Tungsten carbide calibration spheres," Proc. Inst. Acoust. 6(5), 68-75 (1984).

${ }^{27}$ F. H. Dawson, "An inexpensive photosynthetic irradiance sensor for ecological field studies," Hydrobiologia 77, 71-76 (1981).

${ }^{28}$ K. G. Foote, "Speed of sound in Euphausia superba," J. Acoust. Soc. Am. (in press).

${ }^{29}$ K. G. Foote, H. P. Knudsen, G. Vestnes, D. N. MacLennan, and E. J. Simmonds, "Calibration of acoustic instruments for fish density estimation: a practical guide," ICES Coop. Res. Rep. 144 (1987), 69 pp.

${ }^{30}$ E. J. Simmonds, “A comparison between measured and theoretical equivalent beam angles for seven similar transducers," J. Sound Vib. 97, 117-128 (1984).

${ }^{31}$ V. C. Anderson, "Sound scattering from a fluid sphere," J. Acoust. Soc. Am. 22, 426-431 (1950).

${ }^{32}$ R. K. Johnson, "Sound scattering from a fluid sphere revisited,"J. Acoust. Soc. Am. 61, 375-377 (1977).

${ }^{33}$ C. F. Greenlaw, "Acoustical estimation of zooplankton populations," Limnol. Oceanogr. 24, 226-242 (1979).

${ }^{34} \mathrm{U}$. Kils, "Preliminary data on volume, density and cross section area of Antarctic krill, Euphausia superba," Meeresforsch. 27, 207-209 (1979).

${ }^{35}$ D. J. Morris, J. L. Watkins, C. Ricketts, F. Buchholz, and J. Priddle, "An assessment of the merits of length and weight measurements of Antarctic krill Euphausia superba," Br. Antarct. Surv. Bull. 79, 27-50 (1988).

${ }^{36}$ W. H. Hamner, P. P. Hamner, S. W. Strand, and R. W. Gilmer, "Behavior of Antarctic krill, Euphausia superba: chemoreception, feeding, schooling, and molting," Science 220, 433-435 (1983).

${ }^{37}$ T. K. Stanton, "Sound scattering by cylinders of finite length. I. Fluid cylinders," J. Acoust. Soc. Am. 83, 55-63 (1988).

${ }^{38}$ T. K. Stanton, "Sound scattering by zooplankton," Rapp. P.-v. Réun. Cons. Int. Explor. Mer 189 (in press).

${ }^{39}$ T. K. Stanton, "Simple approximate formulas for backscattering of sound by spherical and elongated objects," J. Acoust. Soc. Am. Suppl. 1 84, S219 (1988).

${ }^{40} \mathrm{D}$. V. Holliday and R. E. Pieper, "Volume scattering strengths and zooplankton distributions at acoustic frequencies between 0.5 and $3 \mathrm{MHz}$," J. Acoust. Soc. Am. 67, 135-146 (1980).

${ }^{41}$ H. Bodholt, H. Nes, and H. Solli, "A new echo sounder system for fish abundance estimation and fishery research," Coun. Meet. Int. Coun. Explor. Sea 1988/B:11, Copenhagen.

${ }^{42}$ H. Bodholt, H. Nes, and H. Solli, "A new echo-sounder system," Proc. Inst. Acoust. 11(3), 123-130 (1989).

${ }^{43}$ H. P. Knudsen, "Computer network for fishery research vessels," Proc. Inst. Acoust. 11(3), 115-122 (1989).

${ }^{44}$ H. P. Knudsen, "Bergen Echo Integrator: an introduction," Coun. Meet. Int. Coun. Explor. Sea 1989/B:9, Copenhagen. 